\title{
ACREDITACIÓN DE LA EDUCACIÓN SUPERIOR EN ESTADOS UNIDOS: EL JUICIO DE LOS TRIBUNALES
}

\section{Introducción}

En prácticamente todo el mundo la acreditación de la educación superior ha sido un fenómeno reciente. Los sistemas de acreditación se inician en la gran mayoría de los países sólo a partir de los años 90, a raíz de la expansión y diversificación de la educación terciaria. Se trata de uno de los pilares esenciales en las políticas educacionales relacionadas, ocupando un lugar central en la definición de marcos de regulación de los países y, más recientemente, en la relación entre países ${ }^{1}$.

Estados Unidos constituye un caso especial. Inició procesos de acreditación hace más de 100 años, contando con la más larga tradición y experiencia en el área. El sistema diseñado en EE.UU. es complejo y tiene características que lo hacen único en el mundo. En términos generales, la acreditación allí es responsabilidad de organismos privados -en adelante, agencias de acreditación- que desarrollan y mantienen estándares para las instituciones y/o programas. Las agencias llevan a cabo un proceso voluntario de evaluación destinado a garantizar la calidad de la educación. La importancia de los procesos de acreditación ha crecido fuertemente, particularmente a partir de 1952 cuando, por primera vez, la acreditación fue considerada como requisito básico para el acceso de las instituciones a recursos financieros federales.

1 Efectivamente, el tema de acreditación se ha hecho presente en las diferentes convenciones internacionales e intercambios comerciales, especialmente en lo que se refiere a las normas de elegibilidad, equivalencia y reconocimiento mutuo de la educación postsecundaria y los grados que se otorgan. 
En vista del aumento de poder de las agencias de acreditación y la importancia pública de la acreditación, el Departamento de Educación de EE.UU., USDE (Gobierno Federal) y el Consejo para la Acreditación de la Educación Superior, CHEA (una organización no gubernamental) comenzaron a desarrollar procesos de reconocimiento de las agencias, regulando lo que se consideran prácticas de evaluación y acreditación justas y apropiadas.

Como veremos en el presente trabajo, el papel que desempeñan las agencias implica una compleja relación con las instituciones de educación superior, la cual, en ocasiones, ha sido polémica e incomprendida. Debido a su impacto, existe un conjunto importante de disputas entre agencias de acreditación e instituciones de educación superior que han sido llevadas a la justicia. Este trabajo analiza estos casos y examina su jurisprudencia, cubriendo fundamental aunque no exclusivamente los llevados a tribunales federales. El objetivo del estudio es analizar las lecciones que se desprenden de la jurisprudencia de EE.UU. en cuanto a las prácticas de acreditación y sus límites legales para con las instituciones de educación superior. El periodo de estudio abarca todos los casos registrados en tribunales federales hasta 2005.

Interesa conocer cómo los tribunales entienden a los organismos de acreditación y, en consecuencia, cuál es su opinión respecto de las responsabilidades y alcances de las prácticas de evaluación y acreditación. También analizaré los principios legales involucrados en su relación con las instituciones educacionales superiores, centrándome únicamente en aquellas consideraciones más esenciales y básicas. Más que un estudio jurídico, propiamente tal, este trabajo tiene por objeto exhibir y analizar la opinión de los tribunales en una materia que crecientemente ocupa un lugar central en el debate en educación superior.

Las secciones están organizadas de la siguiente manera: primero, presentaré brevemente el sistema de acreditación de la educación superior en Estados Unidos y sus principales características. 
En segundo lugar, proporcionaré una descripción y análisis de las consideraciones legales que deben contemplarse en la relación entre las instituciones y las agencias de acreditación, detallando la experiencia y opiniones de los tribunales en diversas disputas llevadas a la corte. Finalizaré revisando los principios legales más importantes que se recogen de la experiencia en tribunales, así como la opinión de las cortes de EE.UU. en cuanto a las prácticas de acreditación de la educación superior. Por último, se sugieren algunas reflexiones para discusiones futuras.

\section{La acreditación en Estados Unidos}

Estados Unidos no cuenta con una autoridad central que ejerza un control nacional exclusivo sobre las instituciones de educación superior. La Constitución de Estados Unidos establece que la educación es responsabilidad de cada Estado, quedando ésta regulada con diversos niveles de control, dependiendo de las leyes estatales correspondientes. Pese a que no existe una norma al respecto, es posible decir en general, que los distintos Estados tienden a otorgar niveles considerables de independencia y autonomía a las instituciones de educación superior respecto del gobierno.

De acuerdo con los datos del IPEDS², Estados Unidos cuenta al año 2004 con más de 9.400 establecimientos de educación postsecundaria, de los cuales 4.216 otorgan títulos (degree granting institutions). El número de estudiantes postsecundarios asciende a 17,2 millones y cada año se gradúan 2,8 millones (en los distintos niveles).

La acreditación surge en EE.UU. como una práctica destinada a velar por niveles básicos de calidad de las instituciones de educación superior y sus programas, en el contexto de una considerable expansión y diversificación del sistema. Los orígenes de la acreditación se remontan hacia fines del siglo XIX, con la creación de las primeras asociaciones de colleges y universidades a escala regional.

2 Integrated Postsecondary Education Data System, http://nces.ed.gov/ipeds/ 
En 1909, la North Central Association (NCA) estableció por primera vez un conjunto de estándares correspondientes a los requisitos de elegibilidad para sus instituciones miembros, publicando en 1913 la primera lista de instituciones "acreditadas". Durante los siguientes años las demás asociaciones fueron publicando listas de instituciones acreditadas sobre la base de determinados criterios básicos de membresía. Los orígenes del sistema de evaluación fueron bastante rudimentarios: fundamentalmente, una revisión de información muy elemental presentada por las instituciones antes de ser admitidas por las asociaciones, buscando asegurar ciertos estándares de calidad muy básicos. Paralelamente, lo que hoy se denomina acreditación de programas -o especializada- tuvo sus orígenes en los esfuerzos de asociaciones o colegios profesionales por la evaluación, regulación y certificación de graduados, más que por la evaluación directa de la calidad de la formación entregada por las instituciones. A principios del 1900, la American Medical Association (AMA) -que reúne a los profesionales de la medicina, más que a educadores del área- creó el Council on Medical Education (CME), encargándole la revisión de los egresados de las escuelas de medicina del país. En 1907, el CME publicó por primera vez una lista de las escuelas de medicina que, luego de un proceso de inspección, cumplían con criterios básicos de calidad y que fueron consideradas como "aceptables" (El-Khawas, 2001).

Tanto las asociaciones regionales de instituciones de educación superior como las asociaciones profesionales más importantes del país fueron creando instancias especializadas que, posteriormente, derivaron en agencias de acreditación propiamente tales. Éstas se organizaron crecientemente como instancias de carácter privado, sin fines de lucro y, en la gran mayoría de los casos, con autonomía e independencia de las asociaciones que originalmente las habían formado. Personas de prestigio, expertos en educación, además de académicos y profesionales de trayectoria, ocuparon posiciones en sus Consejos. El sistema de acreditación fue creciendo en tamaño y ganando en experiencia y legitimidad hasta ocupar un lugar central en las regulaciones federales implementadas desde 1952. 
En términos generales, la acreditación en EE.UU. considera dos niveles: institucional y programática -o especializada-. El primero se ocupa de la institución como un todo, generalmente de manera integral, evaluando insumos, procesos y resultados asociados al cumplimiento de los propósitos institucionales ${ }^{3}$. El segundo atiende directamente a los aspectos educacionales implicados en el desarrollo de un programa de formación y sus resultados.

Los procesos de evaluación y acreditación son desarrollados en EE.UU. por tres tipos de agencias de acreditación (Eaton, 2003):

- Agencias regionales: organismos que acreditan a instituciones públicas y privadas, con y sin fines de lucro, con programas de dos y cuatro años. Esto implica una revisión integral de todas las funciones institucionales. La mayoría de las instituciones acreditadas regionalmente otorgan títulos y no tienen fines de lucro.

- Agencias especializadas o profesionales: acreditan programas o escuelas específicas -tales como escuelas y programas de derecho, de medicina, de ingeniería y programas del área de la salud-pertenecientes a instituciones de educación superior. En algunos casos, estas agencias acreditan escuelas independientes.

- Agencias nacionales: destinadas a la acreditación de instituciones públicas y privadas, con y sin fines de lucro, a menudo instituciones con un fin único, incluidos los colleges y universidades, instituciones privadas de carrera y colleges y universidades confesionales. La mayoría de estas instituciones no otorgan títulos y tienen fines de lucro.

Los procesos de acreditación institucional y de programas son voluntarios y periódicos. Habitualmente, las agencias evalúan tomando en consideración los objetivos declarados por la institución o programa (su misión, objetivos y metas) y los criterios externos y estándares definidos por las agencias de acreditación ${ }^{4}$.

3 Cada agencia tiene sus propios criterios para otorgar la acreditación, pero existen ciertas consideraciones generalmente aceptadas.

4 Es necesario considerar las diferencias en cuanto a los elementos contemplados en la acreditación. Algunas agencias prefieren estrictas normas externas, mientras que otras se centran más en los objetivos internos; algunas realizan evaluaciones basadas en un análisis de tipo cuantitativo y otras prefieren una perspectiva más bien cualitativa. 
La forma en que las agencias de acreditación definen si un programa o institución cumple con criterios internos o externos se determina mediante un proceso de evaluación que, comúnmente, consta de tres etapas básicas: autoevaluación, revisión externa y juicio de acreditación. Mientras la autoevaluación es realizada por personal del programa o de la institución, académicos o administradores de otras instituciones (denominados pares evaluadores) se encargan de llevar a cabo la revisión externa. Ambas etapas pretenden analizar cómo el programa o la institución cumple con sus propias metas y los estándares de la agencia, lo cual se sintetiza en informes técnicos que incluyen abundantes datos e información y, en la mayoría de las veces, recomendaciones para mejorar la calidad. Por último, el consejo de la agencia de acreditación otorga o deniega la acreditación, considerando las conclusiones de los informes de evaluación.

Las agencias de acreditación utilizan diferentes aproximaciones para pronunciarse sobre una institución o programa. Algunas se pronuncian provisionalmente sobre programas e instituciones que postulan por primera vez, otorgando una acreditación plena luego de una segunda revisión o pasado cierto tiempo; otras, en cambio, acreditan parcial o totalmente, o bien por un periodo variable, dependiendo del nivel de cumplimiento de los criterios. En cualquier caso, los pronunciamientos son usualmente por periodos determinados, requiriéndose evaluaciones periódicas para mantener la condición de acreditación.

La evolución de las agencias de acreditación en EE.UU ha sido creciente hasta la fecha y con mayor fuerza desde la aprobación de la G.I. Hill, en 1952, en favor de los veteranos de la guerra de Corea. Efectivamente. Esta fue la primera ley que estableció un subsidio federal y un sistema de créditos para realizar estudios en instituciones de educación superior. Inicialmente, limitaba los beneficios a los veteranos de guerra, pero posteriores revisiones consideraron como elegibles a todos los ciudadanos de EE.UU. El elemento central de la ley, que explica la importancia del sistema de acreditación de la educación superior, es que los recursos federales se encuentran 
limitados únicamente a aquellos programas e instituciones acreditados por agencias reconocidas por el Departamento de Educación de EE.UU. (USDE), conforme al Título IV de la Ley de Educación Superior de 1965 y sus posteriores modificaciones.

Evolución del número de agencias de acreditación con reconocimiento y/o acreditación en USA

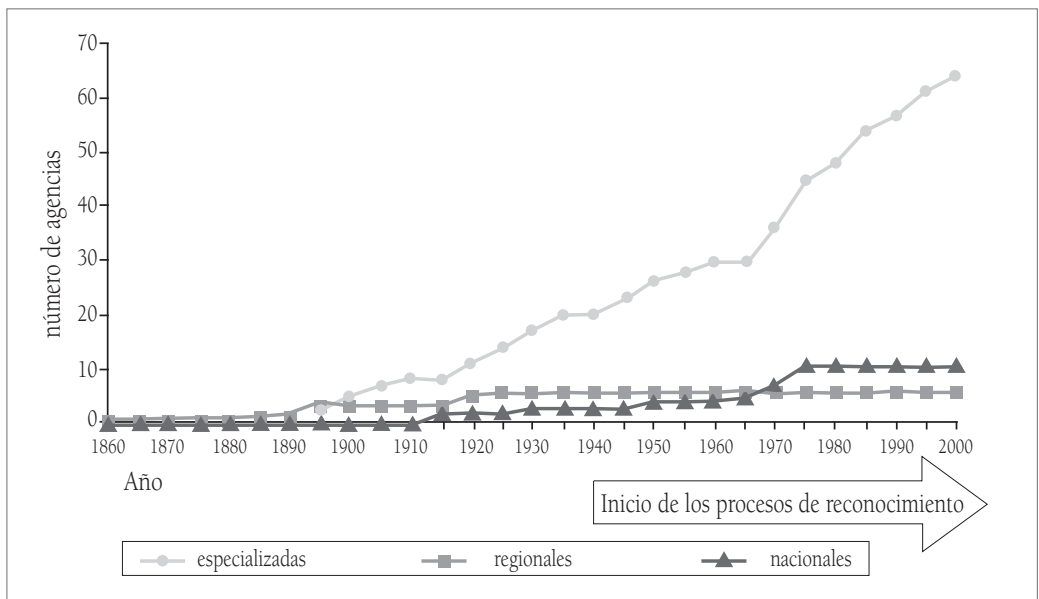

(Zapata \& Salazar, 2003)

Las agencias deben cumplir con los criterios de reconocimiento del USDE y pasar el proceso de supervisión periódica para que sus procesos de acreditación puedan ser válidos para la obtención de fondos federales (y, en ocasiones, fondos de origen estatal). El fundamento del proceso de reconocimiento del USDE es garantizar que los recursos federales sean distribuidos en instituciones con un nivel de calidad apropiado, para lo cual se exige que se encuentren previamente acreditadas por agencias dotadas de la autoridad y la confianza pública suficientes.

Por otra parte, un organismo no gubernamental y sin fines de lucro, el Consejo de Acreditación de la Educación Superior (CHEA), desarrolla un proceso similar denominado de "acreditación de los organismos acreditadores". Se trata de una evaluación de las agencias de acreditación sobre la base de una serie de estándares que acentúan aspectos sustantivos y, fundamentalmente, de orden académico en el funcionamiento de las agencias. CHEA reúne a más de 3.000 colleges y 
universidades americanas y tiene por propósito principal el fomento de la calidad a través de la acreditación voluntaria. Es la continuadora de anteriores organizaciones privadas que desde 1949 realizan esfuerzos por coordinar y robustecer el sistema de acreditación en EE.UU. 5 .

Actualmente se estima que existen alrededor de 180 agencias de acreditación. De acuerdo con los datos proporcionados por CHEA (2001), del total de agencias existentes, 84 cuentan con algún tipo de reconocimiento, ya sea por el Departamento de Educación de EE.UU. o por la propia CHEA. Se trata de seis agencias regionales, 11 nacionales y 67 especializadas. Las restantes, son organizaciones que funcionan al margen del sistema "reconocido" de acreditación, algunas de ellas consideradas como agencias que simplemente operan en el mercado de la venta de certificaciones (Zapata \& Salazar, 2003).

Las agencias de acreditación desarrollan funciones de evaluación y garantía de la calidad a los programas, colleges y universidades ubicadas principal aunque no necesariamente en los 50 Estados del país, el Distrito Federal y demás territorios dependientes ${ }^{6}$. De acuerdo con la información disponible, se contabilizan más de 6.400 instituciones americanas acreditadas por las agencias reconocidas, cifra que comprende instituciones públicas y privadas, con y sin fines de lucro, y de diversos tipos y misiones educacionales. Por su parte, actualmente se registran cerca de 18.700 programas acreditados por agencias reconocidas, incluidos los distintos tipos de programas y niveles de formación postsecundaria.

5 La Comisión Nacional de Acreditación fue la primera, creada en 1949. Años más tarde, se creó la Federación de Comisiones Regionales de Acreditación de la Educación Superior. En 1974 se estableció el Consejo de Acreditación Postsecundaria (COPA), en tanto que en 1994 se creó la Comisión de Reconocimiento de Acreditación Postsecundaria (CORPA). Por último, en 1997 se estableció el Consejo de Acreditación de la Educación Superior (CHEA), organización que desarrolla procesos de reconocimiento de las agencias de acreditación, de modo paralelo a los realizados por el USDE, centrándose fundamentalmente en aspectos de carácter académico.

6 Por ejemplo, Middle States Association of Colleges and Schools (MSA) acredita instituciones en seis Estados, Puerto Rico y las Islas Vírgenes de EE.UU., pero también recientemente en países del lejano Este, África y Europa. La Southern Association of Colleges and Schools (SACS) desarrolla actividades en 11 Estados, pero también ha iniciado actividades en México, el Caribe y Centro y Sudamérica. 
La función primordial de la acreditación es mejorar la calidad de las instituciones de educación superior y sus programas ofrecidos, así como velar por el interés público depositado en ellas. Se trata de enriquecerlas mediante estrategias de evaluación, promoviendo la autorregulación, el aprendizaje de buenas prácticas y la rendición de cuentas; pero también garantizar normas básicas de calidad, proporcionar información a los alumnos y al público, generar confianza entre los empleadores y facilitar la transferencia de créditos, entre los más importantes. La acreditación es requisito para acceder a recursos públicos (en particular, federales), para pertenecer a las asociaciones de instituciones, para que los egresados obtengan licencias de las asociaciones profesionales, entre otros. Recientemente, la acreditación se ha incorporado también como un criterio académico o laboral de aceptación ampliamente extendido, toda vez que se entiende que cualquier institución de razonable calidad debe encontrarse acreditada en Estados Unidos.

Aun cuando, a menudo, se sostiene que el sistema norteamericano de acreditación es de carácter privado, lo cierto es que se trata de un sistema complejo y, de cierto modo, mixto: tanto público como privado. Las agencias de acreditación están operando en un marco de regulación progresivamente más estricto y en el cual crece también el interés público. A menudo, las instituciones deben manejarse simultáneamente con una serie de agencias de acreditación, tanto institucionales como programáticas ${ }^{7}$. Pese a que existe una variedad de agencias, ellas operan circunscritas territorial y profesionalmente, lo que significa que las instituciones tienen un marco muy restringido de elección de agencias, no existiendo competencia real entre éstas, al menos entre las que cuentan con algún tipo de reconocimiento.

Las normas y reglas de las agencias de acreditación pueden variar y surgir conflictos si no hay una comprensión clara de los propósitos, procedimientos y límites del proceso. Las consecuencias

7 Además de las regulaciones estatales que, muchas veces, consideran también algún tipo de evaluación, aprobación o licenciamiento público. 
de la denegación de acreditación son graves y dejan al programa o la institución en una compleja situación de credibilidad, impactando directamente en las posibilidades de competencia por estudiantes con acceso a fondos federales. Principalmente por este motivo, la acreditación y el modo como se desarrolla ha sido fuente de controversias, derivando en un conjunto de disputas entre instituciones y agencias que son llevadas a los tribunales de justicia.

\section{La acreditación y los tribunales en Estados Unidos}

En general, la investigación en educación superior en EE.UU. reconoce el creciente papel político que cumplen los tribunales de justicia en el área, lo que ha llevado a la introducción de diversos principios y criterios derivados de la ley en las prácticas y vida cotidiana de los colleges y universidades (Hines \& Hartmark, 1980). El creciente número de litigios llevados a la corte -lo que algunos denominan "judicialización de la educación superior"- cubre numerosos temas de la vida al interior de los campus: cómo velar por la equidad de género en los deportes universitarios? ¿Qué procedimientos garantizan diversidad y autonomía en la carrera académica? ¿Cómo controlar y penalizar el plagio en la producción académica de estudiantes e investigadores? ¿Cuál es la responsabilidad institucional en los accidentes, crímenes o violencia dentro de los campus?, entre otros. La opinión de las cortes en diversos litigios ha generado una jurisprudencia relevante, por lo que muchos investigadores y administradores han seguido con atención el modo mediante el cual los tribunales nivelan y entienden los derechos y libertades comprometidos en el área.

Debido a la naturaleza del sistema jurídico federal norteamericano (titulo III de la Constitución), las cortes son las responsables de administrar justicia, velando por la protección y libertades garantizadas en la Constitución Política y demás regulaciones, cuando corresponda. El Poder Judicial opera de modo independiente, en un contexto de equilibrio de poderes, lo que usualmente se conoce como "sistema de balances y chequeos entre los distintos poderes del Estado". Una consecuencia inmediata es que las cortes son responsables de nivelar 
y generar jurisprudencia en diversas materias relacionadas con, en este caso, la educación superior.

El sistema jurídico norteamericano se deriva de la Constitución, del derecho consuetudinario y de la llamada "Common Law". Antes de revisar los diversos casos en materia de acreditación, mencionaré las bases de consideración jurídica más importantes referidas exclusivamente a estos casos $^{8}$.

La primera y más importante es la Constitución Política de EE.UU. Ésta no provee referencia específica alguna a la educación, por cuanto cada uno de los Estados miembros es responsable del establecimiento de normas y regulaciones en materia de educación superior. La jurisprudencia indica que la Constitución se aplica en rigor cuando existe acción de Estado o acción de gobierno, esto es, en todos aquellos casos en que se demuestre que existe una acción o autoridad de Estado comprometida. Este elemento de juicio resulta esencial, particularmente en todos aquellos casos de instituciones de educación superior de naturaleza pública y/o que reciben financiamiento federal. Las cortes discriminan entre los casos en los que se ve involucrada la acción de Estado, aplicando el rigor de la Constitución y demás fuentes de la ley, y aquellos en que no lo está, aplicándose entonces las normativas que regulan la acción entre privados. Para los efectos del análisis de los casos en este estudio, interesa considerar la Constitución de EE.UU. particularmente en lo relativo a su primera enmienda (que protege la libertad de expresión, prensa y religión), su catorceava enmienda (que garantiza el debido proceso y la protección igualitaria, entre otros), $y$, en menor grado, su cuarta enmienda (que protege el derecho a la privacidad, a investigaciones y aprehensiones arbitrarias).

La segunda fuente relevante es la Ley de Educación Superior de 1965 y sus posteriores modificaciones. Se trata de la legislación federal que provee estatutos relativos a la distribución de recursos

8 Para mayor información sobre el sistema judicial federal de EE.UU., sus funciones, tipos de cortes y otras materias básicas, ver: http://www.uscourts.gov/library/internationalfinalfinalSpanish.pdf 
en materia de becas y ayudas estudiantiles para las instituciones de educación superior norteamericanas.

Se aplican también las normas y regulaciones administrativas de las agencias asociadas al cumplimiento de la ley, entre ellas, particularmente las establecidas por el USDE y las directamente vinculadas al reconocimiento de agencias de acreditación.

De acuerdo con el sistema norteamericano, se aplican también los precedentes judiciales y las opiniones y decisiones de las cortes, lo que se conoce como el componente crítico de la Common Law.

Adicionalmente, en el nivel estatal corresponde aplicar el conjunto de normas y regulaciones consideradas en la respectiva Constitución, leyes estatales, estatutos y normas administrativas que correspondan.

Finalmente, interesa considerar también un conjunto de normas y regulaciones internas, que incluyen, entre las más importantes, normativas institucionales, contratos y usos y costumbres propios del mundo académico y universitario.

La relación entre las instituciones de educación superior y las agencias de acreditación en los tribunales de EE.UU. ha ido en aumento, principalmente desde mediados de los años ochenta. A continuación, se presentan primero los casos analizados por cortes federales antes de 1980 y que representan el primer conjunto de casos significativos que permiten entender cómo los tribunales identifican la relación entre instituciones y agencias de acreditación.

\subsection{Los primeros casos}

El primer caso llevado a cortes federales data de 1938. La North Central Association of Colleges and Secondary Schools, una de las agencias regionales de acreditación, amenazó con eliminar al State Agricultural College of North Dakota de la lista de colleges acreditados por la asociación, ante lo cual el gobernador del Estado de North 
Dakota solicitó un mandato judicial en contra de la North Central. El tribunal denegó el mandato judicial temporal, aduciendo que no había derecho a intervenir en el procedimiento establecido por la Asociación, en la medida que no existía evidencia de fraude ni arbitrariedad. Considerando que ésta era una agrupación plenamente voluntaria, gozaba de plena libertad para determinar los estándares de afiliación y caducar la afiliación de las instituciones que no cumplieran con dichos estándares. El Tribunal consideró que el College debía tener presente que su relación con la agencia acreditadora era de carácter voluntario, rigiéndose por las propias reglas de la Asociación, en las cuales se contemplaban apropiadamente el derecho a audiencia y reconsideración de sus decisiones y que, por lo mismo, al tribunal no le correspondía intervenir en las medidas adoptadas por la Asociación (Dakota del Norte v/s North Central Association of Colleges and Secondary Schools, 99 F.2d 697, C.A.7 1938).

En 1967 se produjo una situación similar con la misma agencia regional cuando Parsons College - una corporación sin fines de lucro ubicada en Illinois-inició una acción de mandato judicial preliminar con el fin de impedir la decisión de la agencia de no otorgarle la acreditación. Efectivamente, en 1963 la North Central Association colocó a Parsons College en categoría de acreditación condicional y, luego de una evaluación de pares crítica, el Comité Ejecutivo del organismo recomendó que se cancelara su acreditación. Analizados los antecedentes, el Tribunal denegó la moción, considerando que la relación entre el College y la agencia se trataba de una asociación de carácter privado, regida por sus propias reglas, y no correspondía la aplicación de los requisitos constitucionales de un debido proceso sustantivo. Agregó, asimismo, que la Asociación no había actuado en forma arbitraria ni había violado el debido proceso rudimentario, pues se había notificado al College acerca de los cargos por los que se recomendaba la cancelación de la acreditación, otorgándose asimismo la posibilidad de audiencia y estableciéndose las instancias de apelación correspondientes, previas a la cancelación de la acreditación (Parsons College v/s North Central Association of Colleges and Secondary Schools. 271 F.Supp. 65. D.C.Ill. 1967). 
Pocos años después, se presentó una nueva disputa en un tribunal federal. En esta oportunidad, se trató de cargos presentados en contra de la Middle States Association of Colleges and Secondary Schools. La agencia regional se negó a considerar la acreditación de un college privado, el Marjorie Webster Junior College, Inc., estimando que "no era una organización sin fines de lucro que contara con un Consejo Ejecutivo que representara el interés público", conforme con los requisitos establecidos en el reglamento de la Asociación. Luego de que la agencia denegara la consideración para la acreditación, el College inició acciones legales para revertir la decisión de la agencia e imponer su incorporación al proceso, argumentando que los requisitos de la agencia eran arbitrarios y poco razonables, dado que la denegación de la acreditación se debía exclusivamente al carácter particular y los fines de lucro de la escuela, argumento que había sido aceptado por un tribunal de primera instancia9. La Corte Federal determinó que el requisito de la agencia era válido en vista del hecho de que el fin lucrativo podría influir sutilmente en los objetivos educacionales, afectando el ambiente académico. De todas maneras, consideró, con gran deferencia, que la autoridad sobre los temas de carácter académicos le correspondían a la agencia (Marjorie Webster Junior College, Inc. v/s Middle States Association of Colleges E Secondary Schools, Inc. 432 F.2d 650. C.A.D.C. 1970). En esta ocasión, la Corte Federal no emitió opinión alguna sobre la aplicabilidad de la doctrina de la acción estatal, en la cual la actividad de acreditación de la agencia podría ser considerada una acción federal y, por ende, sujeta a las limitaciones constitucionales relativas al debido proceso sustantivo (enmienda 14).

9 Un tribunal de primera instancia ordenó considerar la solicitud del College, en vista de que Middle States "estaba violando la Ley Sherman", ley federal de antimonopolios que data de 1890 y que declara ilegal todo contrato o conspiración tendiente a restringir el comercio y la competencia. Además, determinó que las actividades de la Middle States estaban bajo el control del Gobierno Federal, en una suficiente medida como para que fuera aplicable la cláusula del debido proceso sustantivo; además, por esa sola razón, la denegación de la acreditación a todas las instituciones privadas y con fines de lucro debía ser considerada como arbitraria y no razonable, constituyendo una violación de la Quinta Enmienda. Por último, el tribunal de primera instancia dictaminó que la denegación de la acreditación ocasionaría un daño irreparable a Marjorie Webster Junior Collage, razón por la cual debía ser reconsiderada. 
En 1976, Rockland Institute -una escuela de comercio- inició acciones en contra de Association of Independent Colleges and Schools, cuestionando la revocación de su acreditación, basada en cinco áreas de supuestas deficiencias de la escuela. El Rockland Institute argumentaba que dichas deficiencias ya habían sido subsanadas y que la Asociación estaba aplicando sus reglamentos en forma inadecuada. El reglamento de ésta establecía que, antes de cancelar una acreditación, se debían considerar los siguientes pasos: 1) la institución debía tener la posibilidad de audiencia ante el Consejo de Educación (Board of Commissioners) para discutir el juicio emitido por la agencia, 2) la institución debía recibir notificación previa y por escrito de los procedimientos, los cargos de los que se le acusaba y los criterios conforme a los cuales se le juzgaba, y 3) la decisión de la agencia debía basarse en antecedentes registrados y debía contar con una declaración clara de las razones que respaldaban esta determinación. Al mismo tiempo, en el caso de que la agencia suspendiera la acreditación, se debía otorgar a la institución un plazo específico para solucionar las fallas por las que se adoptaba dicha decisión. Hacia el final del periodo de suspensión, la institución tenía derecho a una nueva audiencia de rectificación, notificada por anticipado y pudiendo tener representación legal, en la cual tenía el derecho a presentar evidencias y ser escuchada. En este caso, el tribunal determinó que se cumplieron todos los pasos necesarios para revocar la acreditación de Rockland Institute. Los demandantes argumentaron que la decisión de cancelar su acreditación no se basaba en evidencia substancial existente en los registros de la agencia. Sin embargo, luego de una revisión minuciosa de éstos, el tribunal encontró evidencia suficiente para sostener la decisión de la Asociación, suspender a la escuela y, posteriormente, cancelar su acreditación (Rockland Institute, Division of Amistad Escuela vocacional, Inc. v/s Association of Independent Colleges. 412 F.Supp. 1015. D.C.Cal. 1976).

Pocos años después, en 1978, un caso similar afectó al Emery School, una escuela de comercio privada del Estado de Massachusetts, manejada por la Marlboro Corporation. Ésta solicitó un mandato judicial cuando la Accrediting Commission of the Association of 
Independent Colleges and Schools estaba analizando la renovación de la acreditación de la escuela. Luego de una evaluación de pares negativa, a la cual la escuela respondió por escrito, la agencia solicitó evidencia adicional respecto de varias áreas que mostraban debilidades, algunas de las cuales tenían relación con su situación financiera. En lugar de cumplir con los requisitos de la agencia, el informe presentado por la escuela daba amplio lugar para denegar la solicitud. La escuela arguyó que la agencia había violado sus derechos constitucionales a un debido proceso y los principios del derecho consuetudinario. Sin embargo, un tribunal de primera instancia y una corte de apelaciones sostuvieron que no se violaron los derechos procesales, apoyando la decisión de la agencia acreditadora. En efecto, aun si la acción de la agencia de acreditación pudiera ser considerada como una acción de Estado, esto es, sujeta a limitaciones constitucionales, la audiencia otorgada a la escuela era un requisito suficiente por el cual se daba cumplimiento al debido proceso (Marlboro Corp. v/s Association of Independent Colleges \& Schools, Inc. 556 F.2d 78. C.A. Mass. 1977). Adicionalmente al tema procesal, la escuela arguyó que uno de los miembros de la comisión de acreditación era rector de una escuela que estaba en competencia directa con la escuela demandante. El razonamiento fue que la decisión de un tribunal imparcial constituye un elemento de debido proceso desde cualquier punto de vista y, en este caso, se determinó que esta persona, a pesar de ser miembro de la agencia de acreditación y, efectivamente, presidente de la Comisión de Acreditación, no participó en la discusión ni votó en la postulación de la Emery School, por lo que no puede presumirse que existió una sentencia indebida.

\subsection{La segunda ola de casos judiciales}

Los casos de Dakota del Norte, Parsons College, Marjorie Webster Junior College, Rockland Institute y la Marlboro Corporation fueron los primeros entre muchos otros que llegaron a tribunales a partir de mediados de la década de 1980. Estos casos establecieron jurisprudencia significativa en lo relativo a la relación entre las agencias y las instituciones de educación superior, incluida una serie de requerimientos de buenas 
prácticas y límites al procedimiento de acreditación, garantizando el respeto a los derechos de las instituciones.

El derecho al debido proceso en la acreditación ha sido motivo de quejas recurrentes por parte de las instituciones de educación superior. Varios casos que implican la denegación de acreditación institucional o programática han sido objeto de juicios iniciados por las instituciones, particularmente cuando se considera que la agencia no ha respetado los requisitos básicos de un debido proceso. Adicionalmente, los demandantes arguyen falta de justicia, arbitrariedad, incumplimiento de las propias reglas de la agencia, normas de evaluación imprecisas y subjetivas, conclusiones o evidencias no determinantes que respalden el fallo de la agencia de acreditación (y la evidencia en los registros) o, bien, que la determinación de la agencia se basa en conclusiones erróneas en relación con los hechos.

A continuación, se presenta un conjunto de casos desarrollados desde mediados de los años 80, lo que he llamado "segunda ola de casos entre instituciones y agencias de acreditación".

Transport Careers, una escuela de educación a distancia localizada en Indiana, inició acciones legales contra una agencia, alegando la violación de sus derechos constitucionales al debido proceso y la igualdad de protección, así como de los principios del derecho consuetudinario y el deber fiduciario. Se trató de una demanda que comprometía nueve quejas específicas, ninguna de las cuales pudo ser comprobada por el tribunal. La corte consideró que la agencia acreditadora había cumplido con sus propias reglas y procedimiento. Asimismo, no fue posible demostrar que las normas de la agencia fueran imprecisas, más bien que en el proceso se habían seguido todos los requisitos del debido proceso (la notificación y la oportunidad de responder, tanto por escrito como verbalmente) y todas las protecciones para asegurar una apelación adecuada a la determinación final tomada por la agencia (Transport Careers, Inc. v/s National Home Study Council. 646 F.Supp. 1474 N.D.Ind.,1986). 
Un año después, el Medical Institute of Minnesota inició acciones legales impugnando la denegación de su reacreditación, quejándose en especial de la falta de imparcialidad de la agencia y de la carencia de evidencia sustantiva en los juicios de la agencia. Nuevamente, el tribunal determinó que las acciones de la agencia acreditadora no eran arbitrarias ni poco razonables y que su decisión estaba adecuadamente respaldada por evidencia contundente. En este caso, analizó también la aplicación de la doctrina de acción estatal, conforme al razonamiento de que las protecciones constitucionales no rigen al no existir una acción del gobierno propiamente tal, aun cuando hay un proceso de reconocimiento federal respecto de la agencia de acreditación (Medical Institute of Minnesota v. National Association of Trade and Technical Schools 817 F.2d 1310 C.A.8 -Minn-,1987).

En 1988, el Royal Business Schools Inc. inició acciones legales solicitando un mandato judicial preliminar con motivo de la denegación de debido proceso por falta de notificación de los procedimientos de audiencias y violación de procedimientos de los derechos de debido proceso del demandante en virtud de la $5^{\text {ta }}$ y $14^{\text {va }}$ enmiendas a la Constitución. La base del argumento se basaba en la teoría de que la denegación de acreditación de parte del demandado constituía una acción estatal. El tribunal dictaminó que los demandantes habían recibido notificación más que suficiente de su procedimiento de acreditación y que el reclamo de violación substantiva al debido proceso carecía de fundamento (Royal Business School, Inc. v/s Association of Independent Colleges and Schools and Accrediting Com'n 1988 WL 98335 E.D.N.Y., 1988).

En 1992 se presentaron dos casos más. Wilfred Academy, seis establecimientos educacionales que otorgan educación en el área de cosmetología en Texas, y Peoria School of Business, una escuela vocacional localizada en Aspen, Illinois, iniciaron acciones legales en diferentes tribunales, reclamando que se les había retirado la acreditación, existiendo faltas a la justicia, arbitrariedad y decisiones poco razonables por parte de las agencias acreditadoras, incluidas infracciones al debido proceso. En el caso de Wilfred Academy, un 
tribunal de primera instancia determinó que los cargos de la agencia de acreditación fueron generales e imprecisos, que la forma en que fue notificada la denegación había sido inadecuada y que las comunicaciones por parte de la agencia se habían realizado de forma incorrecta, todas razones por las que el tribunal otorgó el mandato judicial preliminar. Sin embargo, la Corte de Apelaciones revirtió la decisión de primera instancia en el sentido de que las normas habían sido definidas para profesionales del área de la educación, en un contexto académico donde las normas se entendían suficientemente y que la decisión de la agencia acreditadora estaba respaldada por evidencia suficiente (Wilfred Academy of Hair and Beauty Culture, Houston, Tex. v/s Southern Ass'n of Colleges and Schools 957 F.2d 210 C.A.5 Tex.,1992). En el caso de Peoria School no fue posible encontrar arbitrariedades, toda vez que la evidencia sobre la desfavorable situación financiera de la escuela dejó en claro la urgencia y necesidad de cancelar su acreditación (Peoria School of Business, Inc. v/s Accrediting Council for Continuing Educ. and Training 805 F.Supp. 579 N.D.Ill., 1992).

En 1993, el American Technical College, una escuela vocacional de Illinois con sede en Chicago, recurrió nuevamente al argumento de que la agencia de acreditación actuó como instrumento del gobierno federal, violando los derechos de la escuela al debido proceso, junto con transgredir los principios del derecho consuetudinario de justicia básica. A esto se sumó la existencia de influencias externas en las decisiones del organismo ${ }^{10}$. Al final, debido a la utilización de estándares imprecisos y subjetivos, falta de evidencia igual que en casos anteriores, la solicitud de mandato judicial presentada por el demandante fue denegada (American Technical College v/s Accrediting Council for Continuing Education and Training 1993 WL 62996 N.D.Ill., 1993).

10 Sobre este tema en particular, en este y en otro caso llevado a la corte, se han presentado quejas de una participación ex parte en las deliberaciones del consejo de la agencia acreditadora. Se trata de la asistencia de personal del USDE, el que participa ocasionalmente en calidad de observador en las reuniones de las agencias como parte del proceso de reconocimiento. De acuerdo con lo dictaminado por los tribunales en dos oportunidades, no se considera que la asistencia de observadores constituya una influencia indebida, toda vez que ellos no tienen derecho a voz ni a voto durante las sesiones de las agencias. 
En 1994 se analizaron dos casos más en tribunales. El primero, presentado por el McKeesport Hospital, que lleva a cabo programas de enseñanza de posgrado para médicos. McKeesport obtuvo un mandato judicial preliminar en un tribunal de primera instancia, impidiendo que una agencia acreditadora le retirara su acreditación; sin embargo, la Corte de Apelaciones revirtió la acusación basándose en el hecho de que no se denegó el debido proceso y no se comprobó acción por parte del Estado. Es importante destacar aquí la opinión concurrente de uno de los jueces del tribunal quien, aun cuando estuvo de acuerdo con la mayoría del tribunal en cuanto a que la agencia respetó el debido proceso, arguyó que evidentemente hay una delegación de la autoridad de gobierno en la agencia de acreditación, toda vez que la decisión de acreditación está vinculada, a su vez, a las licencias estatales que se otorgan a los graduados para ejercer la profesión. Por primera vez en un tribunal la opinión se sostiene de que en procesos de acreditación existe acción estatal involucrada (McKeesport Hosp. v/s Accreditation Council for Graduate Medical Education 24 F.3d 519 C.A.3 (Pa.), 1994). Un segundo caso fue presentado por el Chicago School of Automatic Transmissions en contra de una agencia de acreditación que se negó a renovarle la acreditación debido a incumplimiento reiterado en la devolución oportuna de la colegiatura de alumnos que se retiraban de la escuela. Ésta adujo una violación de los reglamentos de la agencia conforme con las leyes del Estado de Illinois. Sin embargo, el tribunal determinó que, en vista de que la acreditación cumple una función federal (analizada recientemente en el Congreso de EE.UU., a raíz de una modificación de la Federal Administrative Act), las agencias de acreditación están obligadas a cumplir con los principios de la ley administrativa federal (Chicago School of Automatic Transmissions, Inc. v/s Accreditation Alliance of Career Schools and Colleges 44 F.3d 447 C.A.7 (Ill.), 1994).

En 1995, el profesor Patrick Rohan, ex decano de St. John's University School of Law, inició acciones legales en contra del American Bar Association, a raíz de una visita a terreno realizada por pares evaluadores. Una de las principales quejas se refería a actos de negligencia por parte de la agencia en la capacitación de 
los evaluadores y la escasa supervisión del proceso en terreno, lo que finalmente resultó -según el demandante- en un informe difamatorio ${ }^{11}$. El conflicto se generó luego que, al final de una visita de terreno, los pares evaluadores realizaran un informe verbal que incluía observaciones sobre serios conflictos académico-administrativos ${ }^{12}$. Ellos basaban sus observaciones en un informe que, aunque no estaba firmado, les fue proporcionado por los académicos, estudiantes y egresados de la escuela. Luego de la visita de pares, la universidad inició acciones en contra del decano, toda vez que los conflictos académico-administrativos fueron abiertamente difundidos. El señor Rohan, por su parte, planteó su queja sobre la forma en que se realizó la evaluación de pares y la falta de oportunidades para hacer frente al informe que lo enjuiciaba directamente. El tribunal falló sobre el caso sin abordar directamente los contenidos ni el modo en que los pares plantearon sus observaciones, y concluyó que la conducta de la agencia acreditadora no era la causa directa de los presuntos daños sufridos por el demandante (Rohan v/s American Bar Ass'n 1995 WL 347035 E.D.N.Y., 1995).

Entre 1996 y 1998 se presentaron dos nuevos casos. Uno fue el del Florida College of Business, el único caso registrado en que una institución educacional ganó un litigio en contra de una agencia acreditadora. Al revisar la acreditación de la escuela, el Accrediting Council for Independent Colleges and Schools encontró una serie de

11 El argumento del profesor Rohan buscaba establecer daños personales por difamación. Cabe mencionar cómo los tribunales resolvieron un conocido caso de supuesta difamación en procesos de acreditación. Se trata de Avis v/s White, en el cual un decano de una escuela de Derecho demandó directamente a un par evaluador que participó en una visita de terreno (pero no se comprometió a la agencia de acreditación). En este caso, los tribunales analizaron cada uno de los comentarios de los evaluadores determinando que, en términos generales, se trataba de expresiones que no se basaban en hechos y, como tales, eran meras opiniones que no podían ser consideradas como difamatorias, toda vez que las ideas, a diferencia de los hechos que las sustentan, no pueden ser falsas. En este caso, se tendió a proteger la libertad de expresión y se consideró como apropiado a la naturaleza de los procesos de evaluación una dinámica de expresiones críticas por parte quienes participan del proceso (Avins v/s White 627 F.2d 637 C.A.Del., 1980).

12 En el informe oral se sostuvo que el decano Rohan no tenía buena disposición, era resentido, inepto, susceptible a los ataques de ira, con tendencias al favoritismo y excesivamente sensible y renuente al cambio, entre otras críticas de carácter personal. 
violaciones a sus normas y decidió cancelarla. Uno de los problemas centrales estaba relacionado con información incorrecta que la escuela había presentado y que sólo corrigió después al momento de apelar a la decisión de la agencia. Sin embargo, la agencia notificó de inmediato al USDE acerca de la denegación de acreditación de la escuela. El tribunal emitió un mandato judicial preliminar de protección a favor de la escuela, dado que los registros de la agencia debían proporcionar evidencia sustancial para respaldar el juicio adoptado y no sólo indicar faltas o errores en la información proporcionada (Florida College of Business v/s Accrediting Council for Independent Colleges and Schools 954 F.Supp. 256 S.D.Fla., 1996). En el segundo caso, el demandante fue Philadelphia Wireless Technical Institute, que inició acciones legales en contra de una agencia, solicitando desagravio por daños y perjuicios. La escuela fue retirada de la lista de acreditación de la agencia luego de que se le dieran varias oportunidades para resolver sus graves problemas financieros. El tribunal no encontró evidencia de arbitrariedad en el proceso y rechazó la solicitud de la escuela (Philadelphia Wireless Technical Institute v/s Accrediting Com'n of Career Schools and Colleges of Tecnología, 1998).

En 2001 se presentaron dos nuevos casos por fraude y falta de aplicación de las reglas y normas de la agencia acreditadora, entre las acusaciones más importantes. En el caso de la Foundation for Interior Design Education Research, visto inicialmente en un tribunal de primera instancia y luego ratificado por una corte de apelaciones, el tribunal introdujo un criterio interesante, al señalar que los procedimientos de acreditación constituyen pautas, pero, si son interpretados en forma demasiado estricta por los tribunales, le quitarían a las agencias la discreción que requieren para evaluar las singulares circunstancias de las diferentes escuelas (Foundation for Interior Design Education Research v/s Savannah College of Art E Design 244 F.3d 521 C.A.6 Mich., 2001). En el caso Ambrose, un grupo de alumnos demandó, simultánea aunque separadamente, al Thomas College y a la agencia de acreditación regional de la cual la institución era miembro, debido a la dudosa calidad del programa de estudios que se encontraban cursando. Adujeron que la agencia no estaba aplicando las normas 
correctas ni estaba haciéndolo rigurosamente, ya que había otorgado la acreditación al College. Sin embargo, el tribunal no encontró evidencias de la mala calidad de la institución, más allá de las declaraciones de los estudiantes, las que, por lo demás, se referían únicamente a uno de sus programas. El tribunal, en cambio, consideró como dato relevante los informes de evaluación de la agencia, dado que ellos daban cuenta de un examen sustantivo del College (Ambrose v/s New England Ass'n of Schools and Colleges 2000 WL 1195363 D.Me., 2000).

El último caso analizado en este estudio corresponde a $2002^{13}$. Auburn University demandó a una agencia regional ante la notificación de que recibiría una evaluación especial. Auburn solicitó el cumplimiento de varias condiciones antes de que la agencia procediera a realizala, sin embargo, el tribunal manifestó que las únicas consideraciones que debían tenerse presente eran las establecidas en las normas y procedimientos de la agencia y las del debido proceso, las que, en general, se habían cumplido. Sin perjuicio de lo anterior, el tribunal enfatizó que una agencia de acreditación debía atenerse a su reglamento y no podía improvisar en un proceso de evaluación (Auburn University v/s Southern Assoc. of Colleges and Schools, Inc. Not Reported in F.Supp.2d N.D.Ga., 2002).

\subsection{Casos adicionales}

Hay una serie de casos no mencionados en que se argumentan criterios de competencia y la ley antimonopolio para limitar las actividades de acreditación de las agencias. En 1989, Joseph Zavaletta, en representación de los alumnos de una escuela de Derecho, inició acciones legales en contra de una asociación profesional que había denegado la acreditación de la escuela. Los demandantes adujeron que las normas de acreditación de la agencia eran subjetivas,

13 Existe también un caso inconcluso presentado en 2004 por la Western State University of Southern CA. La institución obtuvo un mandato judicial preliminar por un tribunal de distrito en el caso de la solicitud de plena acreditación presentada para su escuela de Derecho, alegando que la agencia no había desarrollado el proceso de apelación de acuerdo con las normas y reglas previamente definidas (Western State University of Southern California v/s American Bar Ass'n 301 F.Supp.2d 1129 C.D.Cal., 2004). 
poco razonables y que habían sido aplicadas de manera arbitraria, impidiendo que la escuela compitiera libre y apropiadamente. El tribunal sostuvo que las actividades desarrolladas no implicaban una limitación al comercio y que la opinión de la agencia acreditadora era una manifestación de su autoridad legítima en temas relacionados con la calidad de los programas educativos (Zavaletta v/s American Bar Ass'n 721 F.Supp. 96 E.D.Va., 1989).

En 1996, el Massachusetts School of Law inició acciones basadas en la ley antimonopolio en contra del Colegio de Abogados, luego que se le negara la acreditación. La escuela de Derecho adujo que el organismo estaba violando la Ley Sherman al limitar el comercio mediante políticas que atentan contra la competencia y al conspirar para monopolizar el campo de la educación en Derecho, la acreditación de estas escuelas y el otorgamiento de licencias a los abogados. El razonamiento de los tribunales fue que el organismo había logrado su reputación gracias a su pericia en el tema y que otras organizaciones del área confiaban en su opinión acerca de la acreditación de escuelas en el área. Por lo demás, el tribunal estableció que la Ley Sherman regula comportamientos antimonopolios, pero no opiniones de un organismo que opera de manera independiente en sus deliberaciones (Massachusetts School of Law at Andover, Inc. v/s American Bar Ass'n 952 F.Supp. 884 D.Mass., 1997).

Por último, en 2001, Anita L. Staver et al., alumnos y empleadores de una escuela de Derecho de Florida, iniciaron acciones legales en contra del Colegio de Abogados, argumentando la violación de la ley federal y estatal de antimonopolios, al demorar y denegar la aplicación presentada por la escuela solicitando su acreditación provisional. En esta ocasión el tribunal fue de la opinión que la estructura actual de toma de decisiones del organismo acreditador era producto de sus esfuerzos por cumplir con los reglamentos del USDE, respecto de las agencias de acreditación reconocidas nacionalmente, y que debían respetarse los reglamentos, plazos y procedimientos de la agencia (Staver v/s American Bar Ass'n 169 F.Supp.2d 1372 M.D.Fla., 2001). 


\section{Principales lecciones derivadas de los dictámenes de los tribunales}

Como se ha visto, los tribunales de EE.UU. determinaron que las responsabilidades de acreditación han sido tradicionalmente una función exclusiva entre entidades privadas. Existe una asociación voluntaria entre las instituciones de educación superior y las agencias de acreditación. Sin embargo, existe una tensión por la cual las actividades de acreditación podrían ser consideradas como asuntos cuasi gubernamentales. La mayoría de las quejas de las instituciones han intentado demostrar la aplicación de la doctrina de la acción del Estado, argumentando que las actividades de las agencias deben desarrollarse en los límites constitucionales federales y, particularmente, considerar requisitos estrictos propios del debido proceso sustantivo. Hasta la fecha, los tribunales se han negado a aceptar el argumento de la acción del Estado, a pesar de que, ocasionalmente, reconocen la relación entre acreditación y políticas e interés público en educación, y su relación directa con agencias cuasi gubernamentales y el gobierno federal (particularmente en cuanto al proceso de reconocimiento llevado a cabo por el USDE).

De una u otra forma, los tribunales están conscientes de las consecuencias fundamentales de la acreditación, particularmente cuando se le niega a una institución o programa. Por tal motivo, se presta especial atención a los procedimientos, velando que se respeten los derechos básicos de las instituciones. Sin embargo, los tribunales han tendido a reconocer y respetar las decisiones de las agencias, la definición de sus criterios académicos, reglas internas y dinámicas propias de la evaluación de pares. En la práctica, se trata de un área en que los expertos en educación muestran sus conocimientos especializados y respecto de los cuales los tribunales actúan con gran deferencia.

Los tribunales entienden que la acreditación funciona con sus propias reglas. Las agencias deben operar conforme con los principios del derecho consuetudinario en lo referente a la imparcialidad, 
desarrollando procedimientos que garanticen la falta de arbitrariedad. Debido a que los tribunales estiman que existe el deber de la buena fe y las prácticas leales como parte de la relación especial de confianza y seguridad entre las agencias y las instituciones de educación superior (por la diferencia de poder), las decisiones tomadas por las agencias acreditadoras deben ser razonables, independientes y debidamente respaldadas por evidencia clara, disponible en registros de acceso público. Paulatinamente, los tribunales han tendido a examinar los antecedentes derivados de los procesos de evaluación, pese a que han evitado hacer comentarios sobre su contenido específico.

Aun cuando no corresponde aplicar el debido proceso sustantivo, los tribunales entienden que las agencias de acreditación deben proporcionarlo por razones de equidad y conforme con los principios del derecho consuetudinario. Los requisitos básicos que pueden derivarse de la opinión de las cortes son que las agencias deben: (i) dar la oportunidad a las instituciones de ser escuchadas, (ii) notificar a las instituciones de los procedimientos que les serán aplicados, (iii) notificar a las instituciones, previa y oportunamente, de los cargos específicos que se les formulan, (iv) tener normas de evaluación claras y razonables y que deben ser aplicadas consistentemente, y (v) mantener registro e información sustantiva, susceptible de ser revisada, que respalde sus decisiones.

La acreditación es una actividad que depende de la ayuda mutua y la cooperación entre agencias e instituciones. La literatura en el área reconoce que los procesos de evaluación y acreditación contribuyen a la calidad de la educación superior y que una relación constructiva entre evaluados y evaluadores puede promover mejores prácticas en el área. Aun así, estos procesos pueden llevar a tensiones y conflictos, particularmente cuando las expectativas de una y otra parte no se ven cumplidas. Es posible revisar y realizar los procedimientos regularmente con el fin de tratar de mejorar las prácticas de acreditación y obtener mejores resultados en cuanto a la calidad de la educación. 


\section{Comentarios finales}

Para concluir, se comentan solamente algunos aspectos que, al parecer, pueden contribuir a un cambio en el escenario futuro de la acreditación, así como de sus implicaciones legales.

El objetivo más importante de la acreditación es garantizar (asegurar y promover) además de regular la calidad de la educación superior. Si el proceso se realiza honestamente, se pueden obtener múltiples beneficios internos para mejorar la calidad. Aparentemente, la relación entre las instituciones y las agencias en EE.UU. se ha vuelto en ocasiones conflictiva, presentándose un número importante de litigios en los últimos 25 años. En su mayoría, se trata de controversias relacionadas con cuestiones de procedimiento y sus consecuencias prácticas. Por una parte, el aumento de los casos se debe a la expansión de la acreditación en el sistema, y los tribunales de justicia están para asegurar que el proceso se desarrolle de modo justo y garantizando el respeto de los derechos de las personas y las instituciones. No obstante, la excesiva judicialización de la acreditación puede llevar a limitar la necesaria flexibilidad de un sistema que se rige primordialmente por consideraciones académicas. Parte de la riqueza del proceso puede verse en riesgo si las agencias prestan más atención al desarrollo de procedimientos convencionales en lugar de concentrarse en procesos de tipo sustantivo. Aun cuando los tribunales siguen otorgando amplio reconocimiento al campo de acción de las agencias, es posible observar un movimiento desde los primeros casos hasta los más recientes, en los cuales los tribunales han comenzado a examinar con mayor detención no sólo los procedimientos sino que también los informes y contenidos de las evaluaciones realizadas por las agencias.

No obstante que hasta la fecha los tribunales han sostenido la opinión de que la acreditación es principalmente una actividad realizada por asociaciones de carácter privado, otorgándoles un amplio espacio y deferencia en cuanto a su perspectiva educacional, se ha producido mucho debate en lo referente a la aplicación de la doctrina de acción estatal. En casos recientes, la opinión de los jueces 
ha tendido a resaltar la función e interés público de la acreditación, el fuerte nexo con el gobierno federal a través del sistema de reconocimiento y el uso de recursos federales, la labor que cumple en materia de coordinación y rendición de cuentas, y otros aspectos que, de algún modo, respaldarían al argumento de acción estatal. De más está decir que, de haber un giro en la apreciación de las cortes, las agencias se verían presionadas por un conjunto mucho mayor de restricciones y provisiones de carácter constitucional en el desarrollo de sus procesos.

A lo anterior hay que agregar el creciente aumento del interés público sobre la acreditación. Ya se han comentado los impactos en cuanto al acceso de recursos federales, participación en las asociaciones, reconocimiento de los colleges y el mercado laboral, entre otros. Sin embargo, uno de los temas que está siendo hoy crítico es su relación con la internacionalización de la educación superior, especialmente en cuanto al reconocimiento entre países. La Organización Mundial del Comercio (OMC) y el Acuerdo General sobre el Comercio de Servicios (GATS) han logrado avanzar en las negociaciones para liberar el comercio de servicios, incluida la educación superior. Los organismos de acreditación de Estados Unidos, particularmente CHEA, han tendido a oponerse a la inclusión de la educación superior y la acreditación en estas negociaciones comerciales. Estiman que existe el riesgo de que si la educación superior y la acreditación permanecen dentro del ámbito de acción del comercio internacional del gobierno, la autonomía de la acreditación y su carácter privado se verán claramente sobrepasados por la autoridad central. Por otra parte, diversas comisiones de trabajo han recomendado cambios en la estructura de gobierno de la acreditación -con mayor participación no sólo del gobierno estatal y federal sino que de otros actores-, un fortalecimiento de la relación entre lo público y privado, incluido el sistema de reconocimiento, y un marco nacional más eficiente y transparente de acreditación, entre los temas más importantes.

Pareciera que se avecinan cambios en el modo mediante el cual se entiende la acreditación y que impactarán en su regulación 
y balance público-privado. También las cortes deberán nivelar un tema en el que crecientemente se compromete el interés público y, respecto del cual, lo más probable es que los gobiernos asuman mayor protagonismo del mostrado hasta la fecha.

\section{Referencias bibliográficas}

Eaton, Judith S. (2003) Accreditation and recognition in the United States. Trondheim, Noruega: OECD/Norway Forum on Trade in Educational Services Managing the internationalization of post-secondary education. 3-4 noviembre de 2003.

El-Kawas, Elaine. (2001) Accreditation in the USA: Origins, developments and future prospects". Paris: International Institute for Educational Planning -IIEP-, UNESCO.

Hines, Edward R., and Leif S. Hartmark. (1980) Politics of higher education. Washington, D.C.: American Association for Higher Education.

Kaplin, William A. \& Lee, Barbara A. (1995) The Law of Higher Education: a compressive guide to legal implications of administrative decision-making. Third Edition. Jossey-Bass.

Kaplin, William A. \& Lee, Barbara A. (2000) Year 2000 Cumulative Supplement to: The Law of Higher Education. Third Edition. National Association of College and University Attorneys.

Kells, Herbert R. (1992) Self-regulation in higher education: a multi-national perspective on collaborative systems of quality assurance and control. Great Britain: Biddies Ltd.

Zapata, Gonzalo \& Salazar, José Miguel. (2003) Reconocimiento de agencias de acreditación en educación superior: el caso de los Estados Unidos. Santiago de Chile: Comisión Nacional de Acreditación de Pregrado (CNAP).

Casos judiciales (orden cronológico):

State of N. D. v/s North Central Ass'n of Colleges and Secondary Schools, 99 F.2d 697, C.A.7 1938, Nov 02, 1938.

Parsons College v/s North Central Ass'n of Colleges and Secondary Schools. 271 F.Supp. 65. D.C.Ill. 1967. Jul 26, 1967.

Marjorie Webster Jr. College, Inc. v/s Middle States Ass'n of Colleges \& Secondary Schools, Inc. 432 F.2d 650. C.A.D.C. 1970. Jun 30, 1970. 
Rockland Institute, Division of Amistad Vocational Schools, Inc. v/s Association of Independent Colleges. 412 F.Supp. 1015. D.C.Cal. 1976. Apr 28, 1976

Marlboro Corp. v/s Association of Independent Colleges E Schools, Inc. 556 F.2d 78. C.A.Mass. 1977. May 26, 1977.

Avins v/s White 627 F.2d 637 C.A.Del., 1980. Jun 30, 1980.

Transport Careers, Inc. v/s National Home Study Council. 646 F.Supp. 1474 N.D.Ind., 1986. Nov 03, 1986.

Medical Institute of Minnesota v/s National Ass'n of Trade and Technical Schools 817 F.2d 1310 C.A.8 (Minn.), 1987. May 01, 1987.

Royal Business Schools, Inc. v/s Association of Independent Colleges and Schools and Accrediting Com'n 1988 WL 98335 E.D.N.Y., 1988. Sep 14, 1988.

Zavaletta v/s American Bar Ass'n 721 F.Supp. 96 E.D.Va., 1989. May 05, 1989.

Medical CME Associates v/s Accreditation Council for Continuing Medical Education 1990 WL 160075 N.D.Ill., 1990. Sep 13, 1990

Wilfred Academy of Hair and Beauty Culture, Houston, Tex. v/s Southern Ass'n of Colleges and Schools 957 F.2d 210 C.A.5 (Tex.), 1992. Apr 06, 1992.

Peoria School of Business, Inc. v/s Accrediting Council for Continuing Education and Training 805 F.Supp. 579 N.D.Ill., 1992. Oct 30, 1992

American Technical College v/s Accrediting Council for Continuing Education and Training 1993 WL 62996 N.D.Ill., 1993. Mar 03, 1993.

McKeesport Hosp. v/s Accreditation Council for Graduate Medical Education 24 F.3d 519 C.A.3 (Pa.), 1994. May 17, 1994.

Chicago School of Automatic Transmissions, Inc. v/s Accreditation Alliance of Career Schools and Colleges 44 F.3d 447 C.A.7 (Ill.), 1994. Dec 27, 1994.

Rohan v/s American Bar Ass'n 1995 WL 347035 E.D.N.Y., 1995. May 31, 1995.

Florida College of Business v/s Accrediting Council for Independent Colleges and Schools 954 F.Supp. 256 S.D.Fla., 1996. Dec 19, 1996.

Massachusetts School of Law at Andover, Inc. v/s American Bar Ass'n 952 F.Supp. 884 D.Mass., 1997. Jan 10, 1997.

Philadelphia Wireless Technical Institute v/s Accrediting Com'n of Career Schools and Colleges of Technology, 1998 WL 744101 E.D.Pa.,1998. Oct 23, 1998.

Ambrose v/s New England Ass'n of Schools and Colleges, 2000 WL 1195363

D.Me., 2000. Aug 07, 2000. 
Foundation for Interior Design Education Research v/s Savannah College of Art E Design 244 F.3d 521 C.A.6 (Mich.), 2001. Mar 27, 2001.

Staver v/s American Bar Ass’n 169 F.Supp.2d 1372 M.D.Fla., 2001. Oct 24, 2001.

Auburn University v/s Southern Assoc. of Colleges and Schools, Inc. Not Reported in F.Supp.2d N.D.Ga., 2002. Jan 15, 2002.

Western State University of Southern California v/s American Bar Ass'n 301 F.Supp.2d 1129 C.D.Cal., 2004. Feb 06, 2004.

Recibido: 22 enero de 2007 Aceptado: 14 febrero de 2007 